\title{
Screening for Attention Deficit Hyperactivity Disorder among Korean College Students: Prevalence, Correlates and Comorbidities
}

\author{
Hangoeunbi Kang, MD, Bo-Hyun Yoon, MD, PhD, Kyung-Min Kim, MD, Ha Ran Jung, MD, \\ Yu Ran Jeong, MD, Hyun Ju Yun, MD, Jye-Heon Song, MD, Su Hee Park, MD, Young-Hwa Sea, MD \\ Department of Psychiatry, Naju National Hospital, Naju, Korea
}

\begin{abstract}
Background: The aim of this study was to screen Korean college students for correlates, and comorbidities associated with attention-deficit hyperactivity disorder (ADHD).

Methods: A total of 2,593 college students participated in the study. Socio-demographic and clinical data were collected and self-report scales, such as the Adult ADHD Self-Report Scale-Version 1.1, the Center for Epidemiologic Studies Depression Scale, the Korean version of the Mood Disorder, a modified Korean version of the 16-item Prodromal Questionnaire, and the Alcohol Use Disorders Identification Test were included. Students with and without ADHD were compared using univariable analyses, and the association of ADHD with other psychiatric comorbidities was predicted using multivariable analyses.

Results: Of the total participants, $4.7 \%$ were diagnosed with ADHD. Multivariable analysis revealed that ADHD in college students was significantly associated with depression, psychotic-like experience, alcohol abuse, and female sex after adjustment. We found that ADHD in young college students was associated with several psychiatric comorbidities.

Conclusion: These results suggest the need for early detection of ADHD in young adults and highlight the importance of implementing early psychiatric intervention for problems such as depression, psychotic-like experience, and alcohol abuse in adults with ADHD.
\end{abstract}

Keywords Attention-Deficit Hyperactivity Disorder; Depression; Psychotic-Like Experience; Alcoholism

\section{INTRODUCTION}

Attention-deficit hyperactivity disorder (ADHD) is characterized by inattentiveness, hyperactivity, impulsivity, or a combination of these features [1]. It is the most common behavioral disorder that begins in schoolaged children and is frequently accompanied by serious complications, such as conduct disorder and depressive disorder [1]. Previous studies have found that $30 \%$ to $70 \%$ of individuals diagnosed with ADHD in childhood continue to exhibit full or residual symptoms into adult- hood [2,3]. Although hyperactivity decreases with age, restlessness, inattentiveness, inadequate planning, and impulsiveness persist into adulthood [1,4,5]. Up-to-date diagnostic classifications, such as diagnostic and statistical manual of mental disorders (DSM-5) also define ADHD as a life-long neurodevelopment disorder that begins from childhood and persists into adulthood [1].

The commonly coexisting psychiatric disorders associated with adult ADHD are anxiety disorders, depressive disorder, various kinds of substance use disorders, bipolar disorder (BD) and psychosis [6].

Received July 20, 2019, Revised August 28, 2019, Accepted September 26, 2019

Correspondence: Bo-Hyun Yoon, MD, PhD

Department of Psychiatry, Naju National Hospital, 1328-31 Senam-ro, Sanpo-myeon, Naju 58213, Korea

TEL +82-61-330-4102 FAX +82-61-330-4155 E-mail yoonbh@chollian.net ORCID https://orcid.org/0000-0002-3882-7930

Copyright (C) by Korean Society for Affective Disorders. All Rights reserved.

This is an Open Access article distributed under the terms of the Creative Commons Attribution Non-Commercial License (http://creativecommons.org/licenses/ by-nc/4.0/) which permits unrestricted non-commercial use, distribution, and reproduction in any medium, provided the original work is properly cited. 
As a result of examining the association between ADHD severity and the lifetime prevalence of comorbid depressive episodes in adults between 18 and 60 years, ADHD symptom severity increases in association with lifetime comorbidity with depressive episodes [7].

ADHD patients are more vulnerable to addictions because they try to compensate for the central nervous system's stimulation by immersing themselves in something more stimulating and sensual due to impulsivity and sensation-seeking tendencies [8]. Longitudinal studies have found that childhood ADHD leads to early onset of alcohol use, which can transition into heavy use in young adulthood, and is usually accompanied by conduct disorder or delinquency $[9,10]$.

ADHD and BD are two psychiatric conditions that manifest similar clinical characteristics and diagnostic criteria. Moreover, there exists a strong comorbidity rate that could suggest a more complex relationship between these two disorders [11].

In a large longitudinal study $(\mathrm{n}=1,037)$, adult with schizophreniform disorder were 4 times more likely to have been diagnosed with ADHD as children after adjust other psychiatric diagnosis [12]. In other words, inattention may be an indication to help with the early detection of those at high risk of psychosis. A history of ADHD symptoms in schizophrenia is indicative of poorer psychiatric outcomes [13].

College students are in a transitional period from adolescence to adulthood and are at one of the most important stages in their life. While there is a wide variety of research on depression and anxiety among college students, there is a lack of studies on adult ADHD. College students with ADHD are at greater risk of experiencing academic and psychological difficulties, even though they perform similar to non-ADHD college students on many neuropsychological tests [14]. In the US, students who have been diagnosed with ADHD are well managed as they receive support in relation to education services under the Americans with Disabilities Act [15], but the circumstances are different in Korea.

In addition, ADHD symptoms in adults can be a risk factor for depression, bipolar disorders, psychosis, and substance use disorders and are associated with severe functional impairment [7,9-12,16]. Therefore, the purpose of this study was to examine the prevalence of adult ADHD among college students in their early adulthood and the association with major psychiatric disorders.

\section{MATERIALS AND METHODS}

All surveys were conducted by attendants working in Naju National Hospital or Jeonnam Provincial Mental Health and Welfare Center. A total of 2,598 students enrolled in 13 universities or colleges located in the south western region of Korea were participated.

All subjects joined this study voluntarily and provided a written informed consent. We conducted self-administered questionnaires to collect social demographic and mental health information from the participants such as sex, age, marital status of parents, living arrangement, smoking status, socioeconomic status and utilization of mental health care service. This study was approved by the Institutional Ethics Committee of Naju National Hospital (IRB No. NNH-HR-2019-6).

\section{Measurement}

\section{1) The Adult ADHD Self-Report Scale-Version 1.1}

The Adult ADHD Self-Report Scale-Version 1.1 (ASRS-v1.1) is a screening module in the World Health Organization (WHO) Composite International Diagnostic Interview schedule for use in persons 18 years and older [17]. The screening scale consists of six items with a five-stepped Likert scale $(0=$ never ... 4=very often $)$ and is based on DSM-IV criteria for ADHD [18]. The ASRS showed, after dichotomizing answers (positive rating for items 1-3: $\geq 2$; for items $4-6$ : $\geq 3$ ) and with a cut-off of $\geq 4$, a sensitivity of $68.7 \%$ and a specificity of $99.5 \%$ in a population-based sample [18]. A more recent publication suggested an alternative scoring algorithm with a simple sum score, resulting in a minimum score of 0 and a maximum score of 24 [19]. This study defined the score of 14 or higher as the adult ADHD group $[18,19]$.

\section{2) The Center for Epidemiologic Studies Depression Scale}

The Center for Epidemiologic Studies Depression Scale (CES-D) Consists of 20 items that assess depressive symptoms, rated on a 4-point scale form 0 (rarely or none of the time) to 3 (most or all of the time) [20]. As a result of evaluating the validity of the CES-D Korean version, a total score of 21 or more points was proposed as an optimal cutoff point for primarily screening the clinically significant depressive symptoms [21]. There- 
fore, this study also defined a CES-D score of 21 or more as the depressive disorder group.

\section{3) The Mood Disorder Questionnaires}

Mood Disorder Questionnaires (MDQ) is a selfadministered instrument developed by Hirschfeld et al. [22] for screening bipolar disorder, which was standardized by Jon et al. [23] in Korea. In order to screen positive for possible BD (MDQ responder), all 3 parts of the following criteria must be met: 'yes' to 7 or more of the 13 questions in criteria 1, and these symptoms appear at the same time in criteria 2 , and these symptoms resulted in a functional disorder of more than moderate severity in criteria 3. This study also defined bipolarity (MDQ responder) in case of all three criteria of the MDQ were met.

\section{4) The modified Korean version of the 16-item Prodromal Questionnaire}

This is the modified Korean version of the 16-item Prodromal Questionnaire (mKPQ-16) [24], which is a self-report screening instrument for measuring the risk of early psychosis [25]. mKPQ-16 consists of 16 questions, including 9 questions for hallucination/perception

Table 1. Comparisons of characteristics among Korean college students with and without ADHD

\begin{tabular}{|c|c|c|c|c|}
\hline Variable & $\begin{array}{l}\text { ASRS positive group } \\
\qquad(n=122)\end{array}$ & $\begin{array}{l}\text { ASRS negative group } \\
\qquad(n=2,463)\end{array}$ & $\chi^{2} / t$ & $p$-value \\
\hline Age (y) & & & & 0.634 \\
\hline$\leq 20$ & $93(76.2)$ & $1,827(74.2)$ & & \\
\hline $21-24$ & $26(21.3)$ & $532(21.6)$ & & \\
\hline$\geq 25$ & $3(2.5)$ & $104(4.2)$ & & \\
\hline Sex & & & & $<0.001$ \\
\hline Male & $35(28.7)$ & $1,133(46.0)$ & & \\
\hline Female & $87(71.3)$ & $1,330(54.0)$ & & \\
\hline Marital status of parents & & & & $<0.001$ \\
\hline Married & $89(76.1)$ & $2,153(87.7)$ & & \\
\hline Separated (single, divorce \& widowed) & $28(23.9)$ & 299 (12.3) & & \\
\hline Living arrangement & & & & 0.791 \\
\hline Living with family & $65(55.1)$ & $1,372(56.3)$ & & \\
\hline Living alone & $53(44.9)$ & $1,064(43.7)$ & & \\
\hline Self-reported SES & & & & 0.004 \\
\hline High & $12(10.2)$ & $221(9.0)$ & & \\
\hline Middle & $81(68.6)$ & $1,984(79.6)$ & & \\
\hline Low & $25(21.2)$ & $279(11.4)$ & & \\
\hline Smoking status & & & 2.75 & 0.252 \\
\hline Non-smoker & $90(75.0)$ & $1,966(80.8)$ & & \\
\hline Ex-smoker & $5(4.2)$ & $96(3.9)$ & & \\
\hline Smoker & $25(20.8)$ & $372(15.3)$ & & \\
\hline Utilization of mental health care services & & & 51.36 & $<0.001$ \\
\hline No & $98(81.0)$ & $2,339(95.6)$ & & \\
\hline Yes & $23(19.0)$ & $107(4.4)$ & & \\
\hline \multicolumn{5}{|l|}{ Mental health related conditions } \\
\hline CES-D (score) & $24.1 \pm 12.3$ & $9.8 \pm 8.7$ & & $<0.001$ \\
\hline MDQ (part 1 score) & $8.3 \pm 2.6$ & $5.2 \pm 3.2$ & & $<0.001$ \\
\hline mKPQ (score) & $7.0 \pm 4.1$ & $2.7 \pm 2.8$ & & $<0.001$ \\
\hline AUDIT (score) & $11.7 \pm 8.4$ & $8.4 \pm 6.1$ & & $<0.001$ \\
\hline
\end{tabular}

Values are presented as number (\%) or mean \pm standard deviation

ADHD, attention-deficit hyperactivity disorder; ASRS, Adult ADHD Self-Report Scale-Version 1.1; SES, social economic status; CES-D, Center for Epidemiologic Studies Depression Scale; MDQ, Mood Disorder Questionnaires; mKPQ, modified Korean version of the 16-item Prodromal Questionnaire; AUDIT, Alcohol Use Disorder Identification Test. 
disturbance, 5 questions for thinking disturbance, and 2 questions for negative symptoms. In order to compensate for the lack of items related to cognitive symptoms and ideas of reference compared to perception disturbance, we added No. 4 (ideas of reference), No. 8 (ideas of reference), and No. 38 (attention and speech impairment) of ESI (Eppendorf Schizophrenia Inventory) [26] so that the questionnaire consisted of a total of 19 questions. Participants answer 'yes' or 'no' depending on whether they have the symptoms, and if they answer 'yes,' they indicate the degree of pain on a 4-point scale from 'none' to 'severe' on how difficult their experience is. This study determined the cutoff point as 7 points if the participants answered 'yes' to 7 or more questions.

\section{5) The Alcohol Use Disorder Identification Test}

We used the Alcohol Use Disorder Identification Test (AUDIT), a tool developed by the WHO [27] which is widely used in Korea and other countries due to its simplicity and screening performance. AUDIT consists of 10 questions about alcohol consumption, alcohol dependence, and issues related to drinking during the past year. This study defined an AUDIT score of more than 12 points as problematic alcohol use [28].

\section{Statistical analysis}

This study compared the differences between the
ADHD symptoms group and non-ADHD symptoms group by independent t-test and chi-square test. Logistic regression analyses were performed to analyze the risk factors associated with ADHD symptoms. we included the factors associated with ADHD symptoms in the logistic regression model in terms of univariate analysis. The odds ratios (ORs) and $95 \%$ confidence intervals (CIs) were obtained by logistic regression analysis. This study performed all statistical analyses IBM SPSS Statistics for Windows, Version 22.0 (IBM Co., Armonk, NY, USA) and defined the statistical significance level as $\mathrm{p}<0.05$.

\section{RESULTS}

A total of 2,593 subjects were included in this study, $1,172(45.2 \%)$ were male and 1,421 (54.8\%) female; 2,484 $(95.8 \%)$ were between the ages of 18 and 24 years. There were 2,230 (87\%) subjects who had married parents, and $1,442(56.3 \%)$ subjects living with family.

As a result of the survey, $122(4.7 \%)$ of college students had ADHD. Compared to the non-ADHD group, the ADHD group had more females, divorced/separated parents, lower socioeconomic status, and more utilization of mental health care services in the past. The ADHD group also had higher risk of depressive disorder, bipolar disorders, psychotic-like experience

Table 2. Comparisons of mental health related condition among subjects with and without ADHD in Korean college students

\begin{tabular}{|c|c|c|c|}
\hline Variable & $\begin{array}{l}\text { ASRS positive group } \\
\qquad(n=122)\end{array}$ & $\begin{array}{l}\text { ASRS negative group } \\
\qquad(n=2,463)\end{array}$ & $p$-value \\
\hline Depressive disorder & & & $<0.001$ \\
\hline CES-D $\geq 21$ & $73(61.9)$ & $280(11.5)$ & \\
\hline CES-D $<21$ & $45(38.1)$ & $2,159(88.5)$ & \\
\hline Bipolar disorder (MDQ responder) & & & $<0.001$ \\
\hline MDQ responder & $15(12.9)$ & $39(1.7)$ & \\
\hline MDQ non-responder & $101(87.1)$ & $2,260(98.3)$ & \\
\hline Psychotic-like experience & & & $<0.001$ \\
\hline $\mathrm{mKPQ}$ responder & $56(47.5)$ & $243(10.0)$ & \\
\hline mKPQ non-responder & $62(52.5)$ & $2,196(90.0)$ & \\
\hline Problematic alcohol use & & & $<0.001$ \\
\hline AUDIT $\geq 12$ & $54(46.6)$ & $578(24.1)$ & \\
\hline AUDIT $<12$ & $62(53.4)$ & $1,816(75.9)$ & \\
\hline
\end{tabular}

Values are presented as number (\%).

ADHD, attention-deficit hyperactivity disorder; ASRS, Adult ADHD Self-Report Scale-Version 1.1; CES-D, Center for Epidemiologic Studies Depression Scale; MDQ, Mood Disorder Questionnaires; $m K P Q$, modified Korean version of the 16-item Prodromal Questionnaire; AUDIT, Alcohol Use Disorder Identification Test. 
and problematic alcohol use. There were no statistically significant differences in age, living arrangement, and smoking status between the two groups (Table 1).

A total of 355 (13.8\%) college students were evaluated as the depressive disorder group according to CES-D evaluation, $54(2.2 \%)$ as the BD group by MDQ evaluation, $299(11.7 \%)$ as the psychotic-like experience group by mKPQ-16 evaluation, and $633(25.1 \%)$ as the problematic alcohol use group by AUDIT evaluation. As a result of univariate analysis, ADHD were associated with depressive disorder, bipolar disorder, psychoticlike experience and problematic alcohol use $(\mathrm{p}<0.001$, respectively; Table 2).

Table 3 shows the factors independently associated with ADHD as a result of multivariate analysis. After adjustment, ADHD had a significant relationship with depressive disorder $(\mathrm{OR}=5.46 ; 95 \% \mathrm{CI}=3.32-8.98 ; \mathrm{p}<0.001)$, psychotic-like experience $(\mathrm{OR}=3.76 ; 95 \% \mathrm{CI}=2.31$ $6.11 ; \mathrm{p}<0.001)$, problematic alcohol use $(\mathrm{OR}=2.21 ; 95 \%$ $\mathrm{CI}=1.41-3.34 ; \mathrm{p}=0.001)$ and female $(\mathrm{OR}=1.72,95 \%$ $\mathrm{CI}=1.06-2.79 ; \mathrm{p}=0.029$ ).

\section{DISCUSSION}

The purpose of this study was to investigate the prevalence of adult ADHD among college students in their early adulthood through self-administered questionnaires and the association with major mental disorders. In this study, $4.7 \%$ of college students showed ADHD. As a result of multivariate analysis by correcting other confounders, adult ADHD showed significant associations with female and risk of depressive disorder, psychotic-like experience and problematic alcohol use.

The prevalence of ADHD among college students in this study was similar to the $4.4 \%$ prevalence rate of adult ADHD estimated by a large-scale study in the US [29]. However, it was lower than the $7.6 \%$ prevalence rate of another study in Korea performed on the same basis [30]. According to a recent meta-analysis, the prevalence of adult ADHD was $2.5 \%$ and the prevalence decreased according to the age of both male and female [31]. Up to now, there has been a lack of research on the evaluation, diagnosis, and treatment of adult ADHD compared to pediatric ADHD. In terms of adult ADHD, while major symptoms improve as some symptoms persist and secondary problems cause people to experi-

Table 3. Factors associated with ADHD in Korean college students

\begin{tabular}{|c|c|c|c|c|}
\hline Variable & B & SE & OR $(95 \% \mathrm{Cl})$ & $\mathrm{p}$-value \\
\hline \multicolumn{5}{|l|}{ Sex (reference: male) } \\
\hline Female & 0.54 & 0.25 & $1.72(1.06-2.79)$ & 0.029 \\
\hline Age $(y)$ & -0.04 & 0.05 & $0.96(0.87-1.05)$ & 0.373 \\
\hline \multicolumn{5}{|c|}{ Marital status of parents (reference: married) } \\
\hline Separated (single, divorce, widowed) & 0.09 & 0.07 & $1.09(0.95-1.26)$ & 0.225 \\
\hline \multicolumn{5}{|l|}{ Self-reported SES (reference: high) } \\
\hline Middle & 0.09 & 0.42 & $1.09(0.48-2.50)$ & 0.838 \\
\hline Low & 0.28 & 0.48 & $1.32(0.51-3.41)$ & 0.565 \\
\hline \multicolumn{5}{|l|}{$\begin{array}{l}\text { Utilization of mental health services } \\
\text { (reference: none) }\end{array}$} \\
\hline Yes & 0.64 & 0.35 & $1.89(0.96-3.73)$ & 0.066 \\
\hline \multicolumn{5}{|l|}{ Depressive disorder (reference: no) } \\
\hline Yes & 1.70 & 0.25 & $5.46(3.32-8.98)$ & $<0.001$ \\
\hline \multicolumn{5}{|l|}{ Psychotic-like experience (reference: no) } \\
\hline Yes & 1.33 & 0.25 & $3.76(2.31-6.11)$ & $<0.001$ \\
\hline \multicolumn{5}{|l|}{ Bipolar disorder (reference: no) } \\
\hline Yes & 0.62 & 0.40 & $1.86(0.86-4.03)$ & 0.117 \\
\hline \multicolumn{5}{|l|}{ Problematic alcohol use (reference: no) } \\
\hline Yes & 0.79 & 0.23 & $2.21(1.41-3.34)$ & 0.001 \\
\hline
\end{tabular}

ADHD, attention-deficit hyperactivity disorder; $\mathrm{B}$, unstandardized beta coefficients; $\mathrm{SE}$, standard error; OR, odds ratio; $\mathrm{Cl}$, confidence interval; SES, Social Economic Status. 
ence disabilities in their daily lives [32]. Items that show social, academic, and occupational dysfunctions according to the ADHD diagnosis criteria reveal the effects of ADHD symptoms on adulthood as well as childhood, which require continuing attention and research [1].

Contrary to the previous findings [1,29], this study suggest that ADHD are more associated to women than men. Usually, ADHD is more frequent in males than in females in the general population, with a ratio of approximately $2: 1$ in children and 1.6:1 in adults [1]. However, the differences in prevalence and diagnostic rates according to gender become far less skewed with age, as more women are identified and become diagnosed in adulthood [29,33]. Girls show lower rates of hyperactivity and comorbid conduct disorder than males, and more frequently have the inattentive subtype of ADHD, with a later onset of impairment $[34,35]$. Another study in Korea, sex were not associated with ADHD symptoms [30]. Therefore, futher discussion on the association between sex ratio and ADHD symptoms is needed.

Children with ADHD exhibit carelessness, hyperactivity, impulsivity, and lack of social skills compared to their peers. Adults with ADHD, on the other hand, experience problems in academic or occupational areas and exhibit emotional problems, such as low self-esteem, depression, and difficulty in controlling emotions, and exhibit anti-social behavior, such as substance abuse and alcoholism $[1,6]$. According to a prior study in the US, most adult ADHD patients did not receive treatment for ADHD but received treatment for other psychiatric comorbidities [29]. In this study, depression was a significant variable associated with ADHD symptoms, which was consistent with the results of previous studies $[6,7,30]$. According to a prior study, adults with ADHD and depression had more experience with psychotherapy and pharmacological treatment than subjects with only ADHD [6]. In this case, patients will be treated for depression rather than ADHD symptoms when they start treatment, because the prevalence of depression is high in the department of psychiatry. Likewise, patients will often be under-diagnosed for ADHD when they come to the hospital for treatment [6].

According to previous study, if ADHD is not treated properly, the likelihood of drug abuse will increase and eventually the risk of psychosis will increase accordingly [13]. In a large longitudinal study $(\mathrm{n}=1,037)$, adult with schizophreniform disorder were 4 times more likely to have been diagnosed with ADHD as children after adjust other psychiatric diagnosis [12]. The relationship between ADHD and psychosis may be linked substance use disorder caused by ADHD or may be linked ADHD itself $[12,13]$. This study also showed that there was also a significant relationship between ADHD and the risk of early psychosis. Therefore, ADHD symptoms, such as inattention can be considered as a predictor of psychosis [36]. And futher discussion on the association between psychosis and ADHD is needed.

ADHD and BD are two psychiatric disorders with similar clinical characteristics and diagnostic criteria [11]. Manic episodes of BD are characterized by emotional instability, which can lead to excessive talking and distractions similarly to ADHD, in addition to showing increased activity, physical restlessness, and loss of normal social inhibition. However, patients with BD experience decreased needs for sleep, mental symptoms, hallucinations, and inflated self-esteem, which are symptoms that are difficult to see in ADHD patients [37]. There was no significant relationship between adult ADHD symptoms and BD in this study. On the other hand, according to the previous studies, epidemiological, familial, and neuroimaging studies supported the hypothesis that there is a complex relationship between these two disorders and show a strong coexistence rate, but the exact nature of this relationship is not yet understood [11]. Large-scale studies will need to be performed in the future to identify the relationship between the two disorders.

Substance use disorder is one of the common comorbidities in adult ADHD patients, in which the patients use alcohol, drugs, and cigarettes as a form of selftreatment [37]. This study showed a significant relationship between adult ADHD symptoms and problematic alcohol use, which was similar to the results of previous studies $[9,10]$. ADHD may be a potential cause of substance abuse as well as a factor that can also reduce the prognosis [38]. Therefore, it will be necessary to treat substance abuse patients after diagnosing the prevalence of ADHD.

Patients with ADHD who have been diagnosed with other comorbidities may experience more personal and professional difficulties and may require more mental health services [11]. In this study, major psychiatric disorders, such as depression, psychosis, and problematic alcohol use were also significantly associated with adult ADHD symptoms. In the psychiatric outpatient department, doctors are likely to overlook the evaluation of 
adult ADHD in reality. Patients may also overlook the symptoms due to the lack of awareness of adult ADHD. Psychiatrists need to be aware of adult ADHD in addition to the main complaints of the patient, and also, the evaluation of other comorbidities that may be associated with adult ADHD patients will help the treatment and prognosis of the patient [11].

The limitations of this study are as follows. First, the data from the questionnaires rely on self-administration without consultations with experts, which required attention in interpreting the prevalence of the diseases. Second, there is no information on the prevalence or treatment of ADHD during childhood. Third, there were no evaluations of anxiety disorders, other drug use disorders, and personality disorders that may accompany ADHD. Fourth, cross-sectional studies cannot accurately explain the causal relationship between ADHD symptoms and related factors. A systematic prospective study will be required to identify the causal relationship in the future.

Despite these limitations, this study is meaningful in that it confirms the relationship between adult ADHD and other psychiatric comorbidities. In addition, we hope that interest in the diagnosis and treatment of college students' ADHD will be increased in the field of psychiatric treatment.

\section{CONCLUSION}

This study was performed to assess the ADHD symptoms of Korean college students and to examine the relationship with other psychiatric disorders. This study found that ADHD symptoms in young adulthood were significantly associated with the risk of depression, psychotic like experiences, and problematic alcohol use. Therefore, we need to be aware that ADHD symptoms are also related to other psychiatric disorders in the case of college students. In addition, college students with adult ADHD symptoms will need mental health checkups and follow-up measures to improve academic efficiency and to manage stress.

\section{CONFLICTS OF INTEREST}

The authors have nothing to disclose.

\section{ACKNOWLEDGEMENTS}

Very special thanks to the staffs working in Naju National Hospital or the Jeonnam Provincial Mental Health and Welfare Center. Without their support this work could not have been done.

This study was partly supported by grants from the clinical research fund of Naju National Hospital (NNHHR-2019-6).

\section{ORCID}

\author{
Hangoeunbi Kang \\ https://orcid.org/0000-0002-7106-2757 \\ Bo-Hyun Yoon \\ https://orcid.org/0000-0002-3882-7930 \\ Kyung-Min Kim \\ https://orcid.org/0000-0001-5376-1418 \\ Ha Ran Jung \\ https://orcid.org/0000-0002-1116-1059 \\ Yu Ran Jeong \\ https://orcid.org/0000-0002-0087-0992 \\ Hyun Ju Yun \\ https://orcid.org/0000-0002-6792-7762 \\ Jye-Heon Song \\ https://orcid.org/0000-0001-7370-519X \\ Su Hee Park \\ https://orcid.org/0000-0002-7366-8226 \\ Young-Hwa Sea \\ https://orcid.org/0000-0002-0420-2609
}

\section{REFERENCES}

1. American Psychiatric Association. Diagnostic and statistical manual of mental disorders: DSM-5. Arlington: American Psychiatric Association; 2013. p. 59-65.

2. Barkley RA, Fischer M, Smallish L, Fletcher K. The persistence of attention-deficit/hyperactivity disorder into young adulthood as a function of reporting source and definition of disorder. J Abnorm Psychol 2002;111:279-89.

3. Biederman J, Faraone S, Milberger S, Guite J, Mick E, Chen L, et al. A prospective 4-year follow-up study of attention-deficit hyperactivity and related disorders. Arch Gen Psychiatry 1996;53:437-46.

4. Biederman J, Mick E, Faraone SV. Age-dependent decline of symptoms of attention deficit hyperactivity disorder: impact of remission definition and symptom type. Am J Psychiatry 2000;157:816-8. 
5. Faraone SV, Biederman J, Mick E. The age-dependent decline of attention deficit hyperactivity disorder: a metaanalysis of follow-up studies. Psychol Med 2006;36:15965.

6. Fischer AG, Bau CH, Grevet EH, Salgado CA, Victor MM, Kalil KL, et al. The role of comorbid major depressive disorder in the clinical presentation of adult ADHD. J Psychiatr Res 2007;41:991-6.

7. Simon V, Czobor P, Bitter I. Is ADHD severity in adults associated with the lifetime prevalence of comorbid depressive episodes and anxiety disorders? Eur Psychiatry 2013;28:308-14.

8. Lee MS, Oh EY, Cho SM, Hong MJ, Moon JS. An assessment of adolescent internet addiction problems related to depression social anxiety and peer relationship. J Korean Neuropsychiatr Assoc 2001;40:616-28.

9. Molina BSG, Walther CAP, Cheong J, Pedersen SL, Gnagy EM, Pelham WE. Heavy alcohol use in early adulthood as a function of childhood ADHD: developmentally specific mediation by social impairment and delinquency. Exp Clin Psychopharmacol 2014;22:110-21.

10. Sibley MH, Kuriyan AB, Evans SW, Waxmonsky JG, Smith BH. Pharmacological and psychosocial treatments for adolescents with ADHD: an updated systematic review of the literature. Clin Psychol Rev 2014;34:218-32.

11. Klassen LJ, Katzman MA, Chokka P. Adult ADHD and its comorbidities, with a focus on bipolar disorder. J Affect Disord 2010;124:1-8.

12. Kim-Cohen J, Caspi A, Moffitt TE, Harrington H, Milne BJ, Poulton R. Prior juvenile diagnoses in adults with mental disorder: developmental follow-back of a prospectivelongitudinal cohort. Arch Gen Psychiatry 2003;60:709-17.

13. Levy E, Traicu A, Iyer S, Malla A, Joober R. Psychotic disorders comorbid with attention-deficit hyperactivity disorder: an important knowledge gap. Can J Psychiatry 2015;60(3 Suppl 2):S48-52.

14. Weyandt LL, DuPaul G. ADHD in college students. J Atten Disord 2006;10:9-19.

15. Gordon M, Keiser S. Accommodations in higher education under the Americans with Disabilities Act (ADA): a nononsense guide for clinicians, educators, administrators, and lawyers. New York: Guilford Press; 2000.

16. Biederman J, Faraone SV, Spencer TJ, Mick E, Monuteaux MC, Aleardi M. Functional impairments in adults with selfreports of diagnosed ADHD: a controlled study of 1001 adults in the community. J Clin Psychiatry 2006;67:524-40.

17. Kessler RC, Abelson J, Demler O, Escobar JI, Gibbon M, Guyer ME, et al. Clinical calibration of DSM-IV diagnoses in the World Mental Health (WMH) version of the World Health Organization (WHO) Composite International Diagnostic Interview (WMHCIDI). Int J Methods Psychiatr Res 2004;13:122-39.

18. Kessler RC, Adler L, Ames M, Demler O, Faraone S, Hiripi E, et al. The World Health Organization Adult ADHD SelfReport Scale (ASRS): a short screening scale for use in the general population. Psychol Med 2005;35:245-56.

19. Kessler RC, Adler LA, Gruber MJ, Sarawate CA, Spencer T, Van Brunt DL. Validity of the World Health Organization Adult ADHD Self-Report Scale (ASRS) Screener in a representative sample of health plan members. Int J Methods Psychiatr Res 2007;16:52-65.

20. Radloff LS. The CES-D scale: a self-report depression scale for research in the general population. Appl Psychol Meas 1977; 1:385-401.

21. Cho MJ, Kim KH. Use of the Center for Epidemiologic Studies Depression (CES-D) Scale in Korea. J Nerv Ment Dis 1998;186:304-10.

22. Hirschfeld RM, Williams JB, Spitzer RL, Calabrese JR, Flynn L, Keck PE Jr, et al. Development and validation of a screening instrument for bipolar spectrum disorder: the Mood Disorder Questionnaire. Am J Psychiatry 2000;157:1873-5.

23. Jon DI, Yoon BH, Jung HY, Ha KS, Shin YC, Bark WM. A validation study of the Korean Version Mood Disorder Questionnaire (K-MDQ). J Korean Neuropsychiatr Assoc 2005;44:583-90.

24. Ising HK, Veling W, Loewy RL, Rietveld MW, Rietdijk J, Dragt $S$, et al. The validity of the 16 -item version of the Prodromal Questionnaire (PQ-16) to screen for ultra high risk of developing psychosis in the general help-seeking population. Schizophr Bull 2012;38:1288-96.

25. Kim SW, Chung YC, Kang YS, Kim JK, Jang JE, Jhon M, et al. Validation of the Korean version of the 16-item prodromal questionnaire in a non-help-seeking college population. Psychiatry Investig 2018;15:111-7.

26. Mass R, Girndt K, Matouschek AK, Peter PM, Plitzko N, Andresen B, et al. Introducing the Eppendorf Schizophrenia Inventory (ESI) as a psychometric method for schizotypy research. Personal Individ Differ 2007;42:525-34.

27. Babor TF, de la Fuente JR, Saunders J, Grant M. AUDIT, the alcohol use disorders identification test: guidelines for use in primary care. Geneva: WHO; 2001.

28. Saunders JB, Aasland OG, Babor TF, de la Fuente JR, Grant M. Development of the Alcohol Use Disorders Identification Test (AUDIT): WHO collaborative project on early detection of persons with harmful alcohol consumption-II. Addiction 1993;88:791-804.

29. Kessler RC, Adler L, Barkley R, Biederman J, Conners $\mathrm{CK}$, Demler O, et al. The prevalence and correlates of adult ADHD in the United States: results from the National Comorbidity Survey Replication. Am J Psychiatry 2006;163:716-23.

30. Kwak YS, Jung YE, Kim MD. Prevalence and correlates of attention-deficit hyperactivity disorder symptoms in Korean college students. Neuropsychiatr Dis Treat 2015;11:797802.

31. Simon V, Czobor P, Bálint S, Mészáros A, Bitter I. Prevalence and correlates of adult attention-deficit hyperactivity disorder: meta-analysis. Br J Psychiatry 2009;194:204-11.

32. Johnson DE, Conners CK. Assessment process, conditions 
and comorbidities. In: Goldstein S, Ellison AT, eds. Clinicians' guide to adult ADHD: assessment and intervention. Princeton: Recording for the Blind \& Dyslexic; 2002. p. 71-83.

33. Biederman J, Faraone SV, Monuteaux MC, Bober M, Cadogen E. Gender effects on attention-deficit/hyperactivity disorder in adults, revisited. Biol Psychiatry 2004;55:692-700.

34. Biederman J, Mick E, Faraone SV, Braaten E, Doyle A, Spencer $\mathrm{T}$, et al. Influence of gender on attention deficit hyperactivity disorder in children referred to a psychiatric clinic. Am J Psychiatry 2002;159:36-42.

35. Nadeau KG, Quinn PO. Understanding women with AD/ HD. Silver Spring: Advantage Books; 2002.
36. Erlenmeyer-Kimling L, Rock D, Roberts SA, Janal M, Kestenbaum C, Cornblatt B, et al. Attention, memory, and motor skills as childhood predictors of schizophrenia-related psychoses: the New York High-Risk Project. Am J Psychiatry 2000;157:1416-22.

37. Wingo AP, Ghaemi SN. A systematic review of rates and diagnostic validity of comorbid adult attention-deficit/hyperactivity disorder and bipolar disorder. J Clin Psychiatry 2007;68:1776-84.

38. Ohlmeier MD, Peters K, Kordon A, Seifert J, Wildt BT, Wiese B, et al. Nicotine and alcohol dependence in patients with comorbid attention-deficit/hyperactivity disorder (ADHD). Alcohol Alcohol 2007;42:539-43. 